\title{
AUDITORIA: INDEPENDÊNCIA， ESTRATÉGIAS MERCADOLÓGICAS E SATISFAÇÃO DO CLIENTE - Um estudo exploratório sobre a Região Nordeste ${ }^{1}$
}

\section{Nelson Carvalho}

Professor Doutor do Depto. de Contabilidade e Atuária - FEA-USP

E-mail:Inelson@usp.br

\section{Ruth Carvalho de Santana Pinho}

Professora do Depto. de Contabilidade da FEAAC da

Universidade Federal do Ceará

E-mail: rcspinho@ufc.br

\section{RESUMO}

A crise de credibilidade das auditorias vivenciada não só no Brasil, mas também em países como Estados Unidos e Inglaterra, e o ambiente global, impõem aos auditores independentes uma oportunidade de revisão da forma de condução da sua atividade e de suas principais posturas profissionais. Uma dimensão mais competitiva está influenciando a realidade da Auditoria intensificando, no cotidiano, preocupações com agregação de valor, satisfação do cliente, autoregulação, dentre outras. O fenômeno de migração de valor que acompanha o processo ocorrido, nos últimos anos, de aumento do poder dos clientes, levanta alguns questionamentos acerca da ética, independência e da intensidade da regulamentação governamental na atividade. A argumentação utilizada, neste trabalho, foi fundamentada numa visão temporal do tema, por meio de pesquisa realizada com empresas de Auditoria e respectivos clientes. Sem a pretensão de ser conclusivo, este estudo propõe uma reflexão sobre o desafio de construção de nova realidade.

Palavras-chave: Independência; Auto-Regulação; Foco no Cliente.

\section{ABSTRACT}

The audit credibility crisis, experienced not only in Brazil but also in countries like the United States and England, as well as the global environment impose the opportunity for independent auditors to revise the way in which they conduct their activities and their main professional attitudes. A more competitive dimension is influencing the reality of auditing, intensifying daily preoccupations with added value, client focus, self-regulation, among others. The phenomenon of value migration, which has accompanied the client empowerment process in recent years, gives rise to questions about independence, ethics and governmental regulation. The conceptual principles that guided this work were based on a current view on this matter and on research carried out in audit firms and their clients. Without the intention of being conclusive, this study offers a reflection about the challenge of constructing a new reality.

Keywords: Independence; Self-regulation; Client Focus. 


\section{INTRODUÇÃO}

Há relatos da prática de Auditoria no Brasil desde o início do século passado por empresas de origem estrangeira com filiais aqui implantadas. Entretanto, nas empresas brasileiras foi preciso uma determinação legal para que a mesma fosse adotada. A Lei no 4.728 de 1965, bem como a Lei no 6.385 e a no 6.404 , ambas de 1976, que tratam respectivamente da regulação do Mercado de Capitais, da criação da Comissão de Valores Mobiliários (CVM) e das Sociedades por Ações, foram marcos para a consolidação da Auditoria Independente no Brasil. Não obstante o mérito destas no tocante à garantia de segurança exigida para o mercado de valores mobiliários, as distorções da sistemática impositiva permitiram, a alguns segmentos de usuários, a interpretação equivocada acerca do papel da Auditoria, reduzindo-o à condição de mera atestação de Demonstrações Contábeis.

Carvalho (1989:57-59) assevera que atestar significa afirmar que um conjunto de regras foi seguido ou não. Por sua vez, opinar pressupõe que, seguido esse conjunto de regras, alcança-se ou não o melhor resultado, sob o ponto de vista do auditor. Dessa forma, é possível obter opiniões diversas entre auditores acerca do mesmo conjunto de Demonstrações Contábeis.

Entende-se que o estágio atual da Auditoria deva ser caracterizado por função opinativa, justificando, assim, os pressupostos de qualificação técnica e atributos pessoais exigidos do auditor, bem como o elevado nível de exigência dos usuários e a necessidade crescente de agregação de valor para os clientes.

A realidade que se apresenta para a Auditoria Independente no Brasil é a de mercado ainda restrito e altamente competitivo; de uma imagem ainda em recuperação junto à sociedade, diante de uma fase de desgaste capitaneada pela mídia, do hiato entre as expectativas de auditores e usuários, bem como da relação entre o modelo contábil brasileiro e o padrão de auditoria praticado. Nota-se, ademais, um certo avanço alcançado pelas auditorias internas em termos de resposta às necessidades dos auditados, as quais não passam necessariamente pelos modelos contábeis tradicionais moldados sob a égide de visão do passado.

Dessa forma, este estudo tem como objetivo geral analisar a postura da Auditoria Independente diante da necessidade de agregação de valor para o Cliente e a perspectiva de perda da independência, na perspectiva dos profissionais que atuam na região Nordeste, tomando por base pesquisa realizada em 2001 nas suas três maiores capitais sob o ponto de vista da concentração da atividade.

\section{ASPECTOS METODOLÓGICOS}

\subsection{Definição do problema}

Diante de cenário altamente competitivo, do aumento do nível de exigência dos clientes diante da crescente complexidade do mundo econômico, da rapidez das mudanças e da oferta de serviços profissionais, os mais diversos possíveis, tornase fundamental refletir sobre a atuação da Auditoria Independente.

Compreende-se, portanto, não haver elementos suficientes para refletir-se sobre esses fenômenos numa simples análise extraída do teor das resoluções emanadas do Conselho Federal de Contabilidade (CFC), do Banco Central (BACEN) e da Comissão de Valores Mobiliários (CVM). É preciso, ainda, ouvir as partes envolvidas, ou seja, empresas de Auditoria e clientes, de forma a conferir abrangência às conclusões alcançadas.

Portanto, o espectro que caracteriza a manutenção da independência, em face das estratégias mercadológicas emergentes de satisfação do cliente, carece de investigação cuidadosa de forma a orientar melhor o segmento e, até mesmo, legisladores e órgãos reguladores da atividade.

A independência, atributo técnico e estratégico do auditor, precisa ser preservada, contudo o diferencial competitivo certamente abarca outros elementos. Dessa forma, esta pesquisa contribuiu para esclarecer, à época, quais os aspectos que, efetivamente, precisam ser considerados e qual o nível de interação entre os mesmos, subsidiando, assim, a adoção de uma postura, por parte do auditor, arrojada, mas balizada pela ética e independência.

\subsection{Metodologia}

\subsubsection{Delineamento da Pesquisa}

De acordo com os objetivos da pesquisa, diferentes tipos de procedimentos são adotados para coleta e análise de dados. Dessa forma, realizou-se o 
estudo exploratório-descritivo, de caráter conclusivo e com a coleta de dados realizada de forma estanque, visando estabelecer o relacionamento existente entre as variáveis.

Foi desenvolvida pesquisa de campo buscando identificar, junto às empresas de Auditoria, as estratégias de agregação de valor para o cliente, utilizadas pelas mesmas, bem como a percepção destas quanto à intensidade da regulamentação da atividade. Também, foram obtidas informações acerca do grau de satisfação alcançado com esses serviços. Utilizou-se como instrumento o questionário, sendo um para as empresas de Auditoria e outro para os clientes de auditoria dessas empresas. As perguntas centrais foram preponderantemente fechadas, utilizando variáveis ordinais e aquelas que visavam estabelecer o perfil do entrevistado, semi-abertas, objetivando captar as especificidades da população em estudo.

\subsubsection{População}

A população considerada no primeiro levantamento da pesquisa foi o Cadastro Geral de Auditores Pessoa Jurídica, com registro na Comissão de Valores Mobiliários (CVM), tendo por base os dados de março de 2001, notadamente de empresas de auditoria com sede e/ou filiais nos municípios de Fortaleza, Salvador e Recife, totalizando 29 empresas. Dessa forma, por se tratar de população pequena, a opção mais adequada foi o uso do censo.

De cada empresa, foram também entrevistados alguns clientes, visando mensurar seu nível de satisfação. Foram consideradas como clientes de auditoria para formação dessa população, exclusivamente as companhias abertas, atendidas pelas empresas localizadas na área geográfica supracitada, perfazendo o total de 151 empresas. Detectou-se que muitas, dentre as 151 empresas que constavam do cadastro de clientes de auditoria, estavam desativadas. Dentre essas, algumas em processo de liquidação, outras por suspensão ou cancelamento. Dessa forma, o número de empresas aptas para a pesquisa foi de 61 (sessenta e um). Por se tratar de população pequena, criou-se, assim, a necessidade de, mais uma vez, ser trabalhado o todo, ou seja, foi adotado, também, o censo entre os clientes pesquisados.

\subsubsection{Coleta de dados}

Em ambas as amostras, o questionário foi preenchido pelos respondentes, e enviado via correio, fax ou internet. Os questionários foram previamente identificados e foi assegurada aos entrevistados a confidencialidade das respostas e colocado à sua disposição, número de telefone e endereço eletrônico para dirimir dúvidas.

O questionário aplicado entre as empresas de Auditoria foi composto por trinta questões, divididas em três blocos, a saber: Informações Gerais; Satisfação do Cliente e Conhecimento de suas necessidades; e Independência. Responderam ao questionário os responsáveis técnicos das matrizes e os das regionais, para os casos de empresas com sede fora da área geográfica da pesquisa.

Quanto ao questionário aplicado entre os clientes de auditoria, constam doze questões que visam obter informações quanto ao nível de satisfação alcançado pelos serviços. Nesse caso, os respondentes foram os diretores de relações com o mercado, gerentes de controladoria ou função equivalente.

No questionário aplicado entre as empresas de Auditoria, foi utilizada a escala de Likert², representada por seis pontos, para mensuração de três variáveis, a saber:

- Existência da evidência apontada: escala de 1 a 6, de extremamente fraca até extremamente forte (questões de 7 a 18).

- Importância da evidência apontada: escala de 1 a 6 , de extremamente fraca até extremamente forte (questões de 7 a 18).

- Conseqüência da evidência apontada: escala de 1 a 6 , de extremamente ruim até extremamente boa (questões de 19 a 30).

Quanto ao questionário aplicado entre os clientes, foi utilizada essa mesma escala, sendo dessa vez, analisado o grau de concordância quanto à afirmação lá colocada:

- Concordância quanto à afirmação: escala de 1 a 6, de não concordância até concordância plena (questões de 1 a 12).

${ }^{2}$ Escalas somatórias para medir atitudes que compreendem uma série de afirmações relacionadas com o objeto pesquisado. 


\subsubsection{Tratamento dos dados}

Quanto ao processo de tabulação, os dados dos questionários foram digitados e tabulados no SPSS (Statistical Package for Social Sciences), versão para Windows 10.0, a partir do qual se produziram as análises estatísticas definidas.

Nesse sentido, os procedimentos estatísticos utilizados foram os de caráter descritivo, como a média, o desvio padrão, a mediana e as proporções, cujas possibilidades estatísticas são pertinentes para a escala ordinal utilizada.

\section{ESTRATÉGIAS MERCADOLÓGICAS DE SATISFAÇÃO DO CLIENTE}

Em ambiente de constantes mudanças, propiciado pela relativa facilidade de acesso às informações e pela proliferação de empresas, o nível de exigência dos clientes tem se elevado significativamente e alterado as condições de mercado. No campo profissional, atividades têm sido totalmente redesenhadas para adaptar-se a essas mudanças e, conseqüentemente, atender a tais exigências em termos de tempo, custo e qualidade.

Ohmae (In: Montgomery \& Porter, 1998:68) esclarece que as realidades competitivas formam o ambiente para que sejam testadas as estratégias; contudo, estas são definidas na perspectiva do cliente. $O$ embate entre concorrentes corresponde ao aspecto secundário das mesmas, enquanto a estratégia real equivale ao empenho em conhecer profundamente as necessidades dos clientes.

Certamente, a administração focada no cliente não é tarefa simples, pois requer acompanhamento contínuo da dinâmica do mercado. Nessa economia caracterizada pela migração constante de valor, as prioridades dos clientes mudam a cada instante e, para tanto, é preciso criar fluxo permanente e aberto de informações.

Tais mudanças, à primeira vista, não significam necessariamente novos produtos, e sim soluções ainda inconclusas para problemas do consumidor. Num segundo momento, é preciso adaptar a concepção do negócio ao modelo de lucro adequado. Constata-se, ainda, ser impossível mudar o foco sem alterar a estrutura operacional da empresa. Quando não há os elementos necessários para atender às prioridades do cliente, resta, ainda, a terceirização, o aluguel, o licenciamento, etc.

\subsection{Satisfação do cliente na prestação de serviços}

Téboul (1999:252-254) lança o seguinte questionamento: a inovação e as novas tecnologias estão aptas a melhorar a produtividade e fornecer vantagem competitiva nos serviços, como foi o caso da indústria? Esse autor assevera que a automatização, a robótica, a concepção com auxílio do computador ou o estudo de dados via informática podem ser usados em qualquer atividade, inclusive no setor de serviços.

No que diz respeito aos serviços denominados por Téboul (1999:235-236) de "relativamente" puros, ou seja, realizados por profissionais liberais, são identificadas duas dificuldades quanto à gestão focada no cliente.

A primeira ocorre quando esses profissionais estão ligados à sociedade ou a uma empresa, devido ao baixo nível de domínio da interação com o cliente por parte dessa última. Outro aspecto que acentua a dificuldade é a forte necessidade de independência desses profissionais, dificultando a ingerência da empresa de serviço, em sua atividade.

A segunda prende-se à dificuldade em conciliar a forte orientação técnica dos profissionais com a sensibilidade particular do cliente, notadamente quanto à entrega do serviço e à qualidade no relacionamento.

Nessa categoria de serviços "puros", a estratégia de satisfação do cliente ganha contornos inusitados. O sucesso da estratégia depende muito mais da otimização dos recursos humanos do que dos recursos disponíveis. O gerenciamento deve desempenhar mais o papel de treinamento e motivação e menos de controle. Quanto mais transparente e acessível for o processo de avaliação e o conjunto de indicadores, melhores serão os resultados.

O equilíbrio entre a forte regulamentação dessas atividades, a lealdade a associações de classe, a forte vinculação com a técnica e a credibilidade centrada no processo, em relação à estratégia de satisfação do cliente, ainda é o grande desafio para os profissionais. 
Embora a satisfação das expectativas dos clientes, em relação à qualidade do serviço, agregue valor, esses se ressentem de atenção maior por parte dos profissionais liberais quanto às necessidades que extrapolam as relacionadas ao processo de trabalho.

\section{A AUDITORIA EM FACE DAS ESTRATÉGIAS MERCADOLÓGICAS DE SATISFAÇÃO DO CLIENTE}

A harmonização entre os apelos do mercado competitivo, a clientela exigente e a regulamentação em vigor são o desafio aos profissionais de Auditoria. Versatilidade, criatividade, qualidade e ética são, certamente, componentes imprescindíveis para o êxito dessa empreitada. Vislumbra-se, a partir de uma estratégia ampla, ganhos para os profissionais, instituições e para economia como um todo.

Considerando-se o conceito de estratégias genéricas, estabelecido por Porter (1998:9), a Estratégia de Diferenciação se apresentaria como mais compatível com a natureza da atividade de Auditoria. Neste contexto, entende-se diferenciação como a oferta de serviços que agregam valor para o cliente, pelos quais estaria disposto a pagar até mesmo um preço superior para obtê-los.

\subsection{Estratégia de Diferenciação em Auditoria}

A era do cliente levou as empresas de Auditoria Independente a buscarem adaptação às condições de mercado. O incremento da tecnologia, notadamente da informação, e o aumento do risco dos negócios conduziram esse processo.

Embora tais empresas usufruam relativa tranqüilidade, garantida pela obrigatoriedade legal, estão inseridas em mercado altamente competitivo, o qual pode levar clientes a migrarem para outras empresas prestadoras dos mesmos serviços. A sobrevivência das organizações, não depende mais do fator preço e sim, segundo Gale (1996:26) da combinação entre preço e qualidade, a qual envolve, além da prestação de um excelente serviço, a oferta de vantagens adicionais ao mesmo custo. Guardadas as devidas proporções, a opinião do autor se aplica às prestadoras de serviços de auditoria. Acrescente-se que a conquista do cliente é apenas o primeiro passo a ser dado, pois o cerne da questão é mantê-lo com o padrão de satisfação inicial, tendo em vista que as rápidas mudanças alteram esse patamar a todo momento.

O aumento da demanda por serviços que não de auditoria levou empresas do ramo a incluí-los na carteira de serviços normalmente prestados pelas empresas apenas de consultoria. Tal fato passou a suscitar desconfianças quanto à isenção das empresas de Auditoria, considerando que estariam prestando, concomitantemente, serviços de auditoria e consultoria aos mesmos clientes.

Referidas circunstâncias levaram o Brasil à edição da IN 308/99 da Comissão de Valores Mobiliários (CVM), a qual aponta, no artigo 23, inciso II, a incompatibilidade da prestação de serviços de consultoria a entidades para as quais presta serviços de auditoria das Demonstrações Contábeis. Essas medidas vinham sendo discutidas no âmbito do Conselho de Reguladores de Valores Mobiliários das Américas (COSRA) e foram precipitadas pelos acontecimentos envolvendo falhas empresariais no Brasil e no exterior.

Também nos Estados Unidos, a Securities \& Exchange Commission (SEC), sob a direção de Arthur Levitt havia anunciado, desde 2000, em meio a grandes discussões, regras que proibiam a prestação concomitante de serviços de auditoria e consultoria, obtendo respaldo efetivo do Congresso Americano em janeiro de 2002, com a edição da lei denominada Sarbanes - Oxley Act. Em parte, os escândalos corporativos americanos que envolveram recentemente grandes empresas, dada a repercussão negativa no mercado de capitais americano, puseram fim à polêmica, culminada com a intervenção governamental.

A lei americana é bastante ampla e eleva o grau de responsabilidade das corporações diante da fraude. Abrange não só maior controle sobre as Auditorias visando à garantia de independência e sobre advogados, como, também, acentua a responsabilidade corporativa, instituindo regras e severas punições para administradores envolvidos em artifícios para lesar os usuários das informações.

As ações de órgãos reguladores e de governos indubitavelmente estimulam a cultura acionária e propulsionam a economia mediante a segurança que inspiram. Depreende-se, contudo, que o problema não se esgota na questão regulatória. Para expandir mercados, adquirir credibilidade e garantir a 
sobrevivência, a Auditoria deve recorrer aos princípios da estratégia competitiva, pautada sempre no padrão ético requerido para a profissão, constatação essa extraída da pesquisa antes mencionada.

\section{A PESQUISA}

Este tópico se propõe a apresentar e discutir os resultados de pesquisa de campo realizada no contexto de desenvolvimento de Dissertação de Mestrado (Pinho: 2001), desenvolvida com empresas prestadoras de serviços de auditoria e os respectivos clientes, selecionados conforme um plano amostral que trata dos aspectos metodológicos que caracterizam o estudo.

\subsection{Ambiência e caracterização do objeto de estudo}

O domínio das empresas de Auditoria de origem estrangeira e a ausência de maiores desafios de mercado possivelmente conduziram, por muito tempo, profissionais e empresas do setor à postura distanciada do conhecimento das necessidades dos clientes.

Demandada por algumas organizações com o único propósito de atender aos ditames legais ou estatutários, além de ter o alcance engessado pela normatização, a Auditoria experimentou, no Brasil, a perda da porção mais nobre da missão que lhe é atribuída, ou seja, opinar, de forma clara, sobre a consistência do objeto de exame, consoante os objetivos para os quais foi contratada, com autonomia para definir a natureza e a extensão do trabalho.

Conceitos relacionados à ética, moral e principalmente independência, foram incorporados sob a ótica do órgão regulador. Nas referidas circunstâncias, o processo de evolução foi interrompido para dar lugar à argumentação, sob a ótica do regulador, da necessidade premente de transparência segundo critérios impostos e credibilidade presumida.

No decorrer da análise dos resultados, a localização geográfica e o perfil dos que se sensibilizaram diante do apelo da pesquisa representam, também, um aspecto a ser considerado. A ausência de tradição na atividade de Auditoria nas três capitais nordestinas pesquisadas (Pinho: 2001), e o baixo índice de respostas por parte das empresas mais representativas, como as big four ${ }^{3}$ contribuíram, decisivamente, para que houvesse um pouco mais de cautela na análise.

\subsection{Apresentação e análise de dados - Empresas de auditoria}

Os itens, a seguir, contêm os dados coletados, tratados estatisticamente, e a análise dos resultados da pesquisa de campo. Foram recebidas respostas de 11 dos 29 questionários endereçados às empresas de Auditoria (37,93\%), dentre as quais, 3 das big four, e 26 dos 61 questionários enviados para as empresas clientes $(44,26 \%)$.

\subsubsection{Perfil das empresas de Auditoria}

Serão abordadas, neste item, as questões de 1 a 6, contidas no Bloco I - Informações Gerais, objetivando caracterizar o perfil das empresas participantes para, posteriormente, associá-los às respostas das demais seções.

\section{a) Localização}

Fortaleza alcançou maior participação (6); enquanto Salvador (3), cerca da metade. A menor foi a de Recife (2). Ressalte-se que, dentre as empresas de Auditoria pesquisadas, apenas duas não foram localizadas pelo endereço que constava no cadastro consultado.
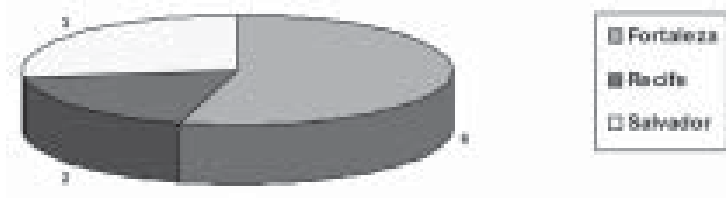

\section{Gráfico 1 - Participação conforme localização geográfica}

\section{b) Carteira de Clientes}

A carteira de clientes é, predominantemente, composta por empresas comerciais e de prestação de serviços (7). As indústrias vêm em segundo lugar (3) e a menor participação foi das estatais e empresas públicas (1).

${ }^{3}$ Quatro grandes empresas de Auditoria no mundo. 

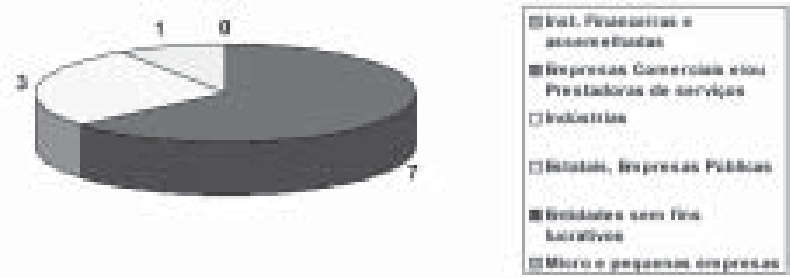

Gráfico 2 - Composição da carteira de clientes

\section{c) Tamanho da equipe de Auditoria}

Equipes com 1 a 50 auditores representam a maior incidência na população estudada (9), enquanto equipes compostas por 51 a 100 auditores (2) dão menor contribuição ao estudo. Não foram encontradas equipes nas faixas entre 100 e 300; mais de 300 funcionários; ou ainda, com mão-deobra terceirizada.
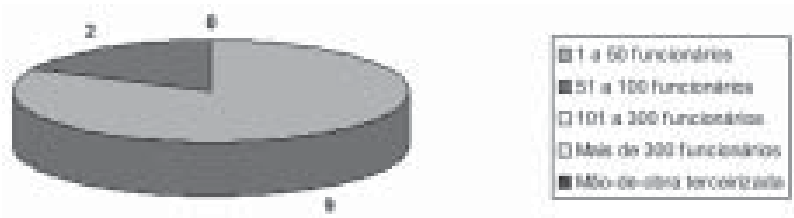

\section{Gráfico 3 -Tamanho da equipe de auditores}

\section{d) Tempo de Relacionamento}

O tempo de relacionamento compreendido entre 1 a 3 anos, representa quase metade (5) das evidências levantadas e relacionamentos de 3 a 5 anos ocupam a segunda posição (3). Tanto os relacionamentos mais curtos quanto os que compreendem o período de 4 a 12 meses, e os relacionamentos acima de 5 anos e questões não respondidas apresentam um caso cada.
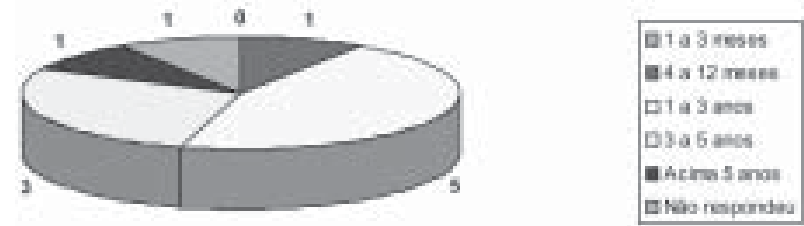

\section{Gráfico 4-Tempo de relacionamento com clientes}

\section{e) Tipos de Auditoria}

A Auditoria das Demonstrações Contábeis (11) é realizada por todas as empresas participantes. Algumas que realizam mais de um tipo de Auditoria declararam fazer, também, Auditoria Operacional e de Gestão (7), Auditoria Tributária (5) e Auditoria de Sistemas (2).
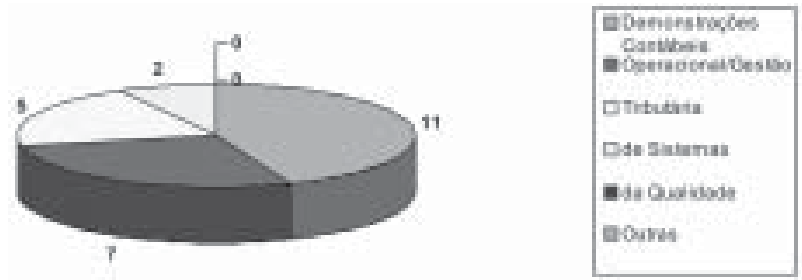

Gráfico 5-Tipos de Auditoria

\section{f) Formas de demanda}

A pesquisa revelou que a demanda por serviços de Auditoria ocorre, em sua maioria, por obrigações contratuais (6). A obrigação legal/regulamentar (4) vem, em seguida, refletindo o tamanho do mercado de capitais na região. A demanda espontânea ocorreu em 3 casos e, quanto às outras formas citadas na pesquisa, com uma única resposta, foi mencionada a licitação.
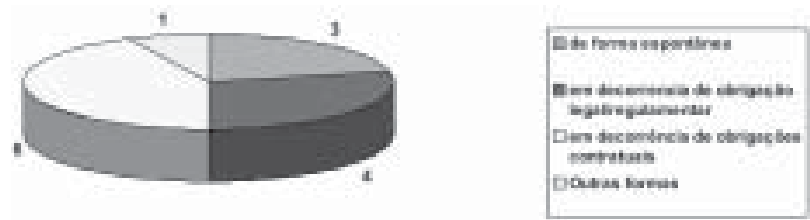

Gráfico 6 - Motivação para demanda por Auditoria

\subsubsection{Resultados relativos à Satisfação do Cliente e Conhecimento de suas necessidades}

Da tabela 01 extraem-se, em níveis gerais, as discrepâncias entre os aspectos analisados quanto às variáveis Concordância/Existência e Importância das situações propostas no questionário. Em relação aos resultados do bloco I - Satisfação do cliente e conhecimento de suas necessidades foi identificado um gap de 0,49 entre a Concordância e a Importância. Tal diferença ressalta a existência de prática levemente dissonante do discurso das empresas.

Quanto aos resultados do bloco II - Independência, um gap de -0,13 indica que os entrevistados consideram fracas as repercussões das atuais práticas da atividade sobre a independência do auditor propriamente dita. Entende-se que a independência, na visão dos entrevistados, depende de outros fatores e não unicamente das regras da profissão. 
Tabela 01 - Gap entre as variáveis

\begin{tabular}{|c|c|c|c|}
\hline Atributos/itens & $\begin{array}{l}\text { Concordância/ } \\
\text { Existência }\end{array}$ & $\begin{array}{l}\text { Importância/ } \\
\text { Conseqüência }\end{array}$ & $\begin{array}{l}\text { Lacuna/ } \\
\text { Gap }\end{array}$ \\
\hline \multicolumn{4}{|l|}{ Bloco I } \\
\hline Monitoramento satisfação cliente & 4,27 & 5,55 & 1,28 \\
\hline Liberdade-autonomia para encaminhamento reclamação do cliente & 5,09 & 5,36 & 0,27 \\
\hline Módulos de treinamento estimular capacidade auditores & 4,27 & 5,27 & 1,00 \\
\hline Atestação de fidedignidade Demonst. Contábeis como forma de agregar valor & 4,64 & 4,82 & 0,18 \\
\hline Conhecimento do cliente & 4,45 & 4,82 & 0,37 \\
\hline Melhoria qualidade via trabalhos adicionais & 4,64 & 5 & 0,36 \\
\hline Oferta serviços adicionais & 5,27 & 5,73 & 0,46 \\
\hline Cobrança separada serviços adicionais & 5,55 & 5,73 & 0,18 \\
\hline Solicitação serviços adicionais & 2,80 & 2,8 & 0,00 \\
\hline Instrumentos medição satisfação cliente & 3,45 & 4,45 & 1,00 \\
\hline Índice satisfação serviços prestados & 4,91 & 5,55 & 0,64 \\
\hline Promoção manutenção e intensificação pelas pessoas-chave & 5,00 & 5,18 & 0,18 \\
\hline Média & 4,53 & 5,02 & 0,49 \\
\hline \multicolumn{4}{|l|}{ Bloco II } \\
\hline Contratação auditoria por obrigação legal & 3,73 & 2,45 & $-1,28$ \\
\hline Não atendimento necessidades pelos serviços de atestação & 3,82 & 3,55 & $-0,27$ \\
\hline Comprometimento independência auditor com serviços adicionais & 2,55 & 4 & 1,45 \\
\hline Ausência maior conhecimento por parte de magistrados & 4,27 & 4 & $-0,27$ \\
\hline Aprovação convívio atividades auditoria e consultoria & 3,18 & 3,7 & 0,52 \\
\hline Prejuízos para investidores com perda independência do auditor & 5,27 & 3,1 & $-2,17$ \\
\hline Recomendações no Relatório Sugestões como forma de consultoria & 4,91 & 5,2 & 0,29 \\
\hline Extensão da auditoria obrigatória a todas às empresas & 4,91 & 5,4 & 0,49 \\
\hline Elevado custo Auditoria Independente como entrave à expansão & 3,09 & 2,55 & $-0,54$ \\
\hline Temeridade pela falta fiscalização e punição para auditores & 3 & 3,36 & 0,36 \\
\hline Retrocesso em face da proibição serviços consultoria por auditores & 4,64 & 3,45 & $-1,19$ \\
\hline Perda competitividade por excesso rigor regulatório da atividade & 3,36 & 4,36 & 1,00 \\
\hline Média & 3,89 & 3,76 & $-0,13$ \\
\hline
\end{tabular}

Fonte: Compilado pelo SPSS

\subsection{Apresentação e análise de dados - Empresas-cliente de auditoria}

As questões analisadas neste tópico envolvem as respostas obtidas dos clientes das empresas de auditoria, entrevistadas no anterior. Para tanto, foram utilizadas a média aritmética, a mediana e o desvio padrão.

\subsubsection{Perfil dos entrevistados}

Objetivando análise mais apurada das respostas, foi levantado o perfil dos entrevistados, envolvendo basicamente dois aspectos, a saber: cargo que ocupa e tempo de serviço na empresa.

\subsubsection{Cargo que ocupa}

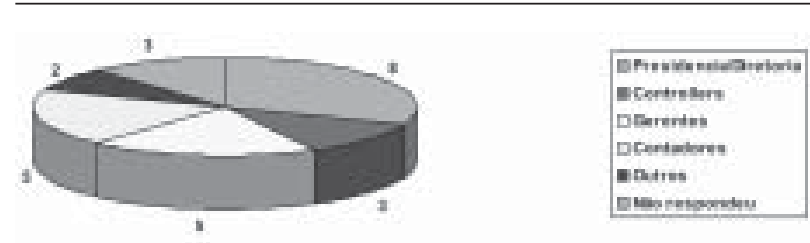

\section{Gráfico 7 - Ocupação dos entrevistados}

O gráfico demonstra que dezoito dos vinte e seis respondentes ocupam funções de presidência ou diretoria (8), gerência (5) e de contabilidade (5). Os controllers (3) e outros (2), que se identificaram como assessores, representaram a menor contribuição. Deixaram de responder ao quesito três dos entrevistados.

\footnotetext{
${ }^{4}$ Discussões sobre riscos empresariais já são bastante comuns nos Relatórios de Administração de empresas americanas e européias, mas são ainda muito raras entre as empresas brasileiras de capital aberto.
} 


\subsubsection{Tempo de Serviço na empresa}

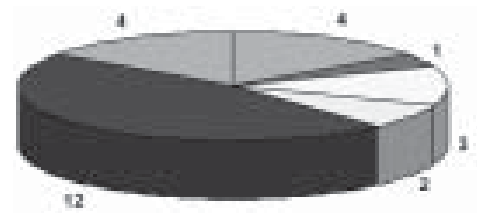

Gráfico 8 - Tempo de Serviço na empresa
Observa-se que doze, dentre vinte e seis entrevistados, trabalham há mais de 15 anos na empresa; dois, entre 10 e 15 anos, e três entre 6 e 10 anos. Dentre os que têm menos tempo de serviço estão os que trabalham entre 3 e 5 anos (1) e entre 0 e 2 anos (4). Deixaram de responder ao quesito quatro dos entrevistados.

\subsubsection{Aspectos de satisfação sob a ótica do cliente}

A tabela 02 apresenta os resultados obtidos, nos quesitos aplicados entre os clientes de Auditoria. Conforme a escala de valores estabelecida na metodologia de trabalho, foram alcançadas as seguintes médias:

Tabela 02 - Aspectos de satisfação sob a ótica do cliente

\begin{tabular}{|c|c|c|c|}
\hline Quesitos & Média & Mediana & $\begin{array}{l}\text { Desvio } \\
\text { padrão }\end{array}$ \\
\hline Manutenção de contato constante com o cliente & 4,96 & 5 & 0,87 \\
\hline Reclamações ouvidas atentamente e encaminhadas prontamente & 4,65 & 5 & 0,85 \\
\hline Interesse em manter relacionamento de longo prazo com auditoria & 5,27 & 5 & 0,72 \\
\hline Conhecimento por parte do auditor de negócios/necessidades & 5,35 & 6 & 0,80 \\
\hline Agregação de valor pela empresa de auditoria & 4,52 & 5 & 0,92 \\
\hline Trabalhos adicionais melhoram qualidade da auditoria & 4,46 & 5 & 0,99 \\
\hline Comprometimento da independência por haver serviços adicionais & 3,31 & 3 & 1,64 \\
\hline Serviços de atestação não atendem plenamente às necessidades & 4,5 & 5 & 1,77 \\
\hline A empresa faz solicitação constante de serviços adicionais & 1,77 & 1 & 1,31 \\
\hline Aplicação constante de instrumentos formais de medição do nível de satisfação & 3,08 & 3 & 1,70 \\
\hline Transtornos por rotatividade obrigatória de empresas de auditoria & 3,12 & 3 & 1,80 \\
\hline Empresa de auditoria demonstra preocupação em satisfazer o cliente & 5,19 & 5 & 1,06 \\
\hline MÉDIA & 4,18 & - & 1,20 \\
\hline
\end{tabular}

Fonte: Compilado pelo SPSS

Observa-se que os aspectos indicadores de satisfação do cliente oscilam entre fortes e muito fortes, exceto no que diz respeito à aplicação de instrumentos formais de medição dessa satisfação, com média 3,08 (fraca). Fica constatada essa situação quando se compara o resultado com o gerado pelas empresas de Auditoria $(3,45)$. Embora estas últimas tivessem considerado a ferramenta de forte importância $(4,45)$, evidencia-se aqui que não a têm utilizado.

\section{CONCLUSÕES}

O novo paradigma que emerge, no contexto da Auditoria, pelos resultados da pesquisa regionalizada levada a cabo neste estudo indica a necessidade de incorporar, ao rol de atributos intuitivamente obrigatórios (tais como o domínio do conhecimento sobre os Princípios Fundamentais de Contabilidade e sobre Normas de Auditoria, por exemplo), as competências pessoais, a tecnologia e a compreensão estratégica do negócio. Às expectativas predefinidas para o trabalho do auditor, deve ser somado o diferencial nos serviços, captado a partir de profundo conhecimento das necessidades dos clientes.

Os esforços de conquista e manutenção de clientes, notadamente, deverão ser balizados pela ética e qualidade técnica do profissional. Não se trata de teoria vazia, de incentivo à cordialidade nas relações, mas sim da identificação de o que, efetivamente, gera valor para os usuários. A resposta, certamente, virá também na forma de valor, entendendo-se, como tal, margens elevadas, credibilidade e, por fim, sustentabilidade. $O$ desafio que emerge dessa 
atuação é o de manter a independência e atender às expectativas do contratante dos serviços de Auditoria.

As empresas-cliente, na média, demonstraram índices fortes de satisfação, e sensibilidade aguçada para os aspectos de agregação de valor e relacionamento. Embora tenham apresentado motivação para manutenção de relacionamentos, confirmaram a tendência de constante migração de valor existente no segmento, conclusão essa influenciada pelo perfil das empresas pesquisadas, notadamente no aspecto do tempo de relacionamento.

Como todas as empresas pesquisadas oferecem serviços de Auditoria das Demonstrações Contábeis cujo produto final, qual seja, o Parecer dos Auditores sobre Demonstrações Contábeis, tem feições relativamente padronizadas, correm o risco de não estarem habituadas a lidar com a expectativa dos clientes. De certa forma, esses fatores deixam-nas despreparadas para a busca de relacionamentos mais profundos. Os indicadores coletados que apontam atenção maior ao cliente não se revestem de caráter estratégico tendo em vista que, embora ocorram com determinada freqüência, não são ações articuladas.

Uma questão a ser aprofundada em futuros trabalhos diz respeito à postura dos clientes, e de analistas e outros usuários de demonstrações contábeis auditadas, face kao rodízio de auditores instituído pela $\mathrm{CVM}^{4}$. Ressalte-se que esses mesmos clientes haviam se declarado satisfeitos e dispostos a manter relacionamentos duradouros. Depreende-se daí que efetivamente não foram fidelizados, mas simplesmente mantidos. Trata-se, praticamente, de uma relação de tolerância deles para com os auditores, suportável até que estes últimos frustrem as suas expectativas de maneira significativa.

O grande desafio está em reafirmar junto aos investidores, de forma clara e inequívoca, a independência e, conseqüentemente, a credibilidade do trabalho do auditor. No que diz respeito a clientes, a questão parece bem resolvida, inclusive com o entendimento de que a prestação de serviços outros, de forma concomitante à Auditoria, melhora, sensivelmente, a qualidade das informações. Evidenciou-se que a integridade do grupo de profissionais não poderia ser questionada pela leviandade do pré-julgamento, por conclusões precipitadas. A perda de independência se configura quando é comprovado, de fato, o conflito de interesses do auditor, contudo a regulamentação governamental tem o mérito de ser preventiva.

A pesquisa (Pinho: 2001) leva a crer que os clientes não são tão sensíveis ao preço quanto à qualidade. Acredita-se que, à medida que o trabalho é comprovadamente agregador e também preservador de valor, as possibilidades de ganho são amplas, haja vista que os clientes não questionariam honorários e o mercado seria receptivo. A expansão da atividade está atrelada à qualificação da equipe, à integração com outros profissionais, ao uso do marketing, à reciprocidade ao cliente, ao uso intensivo de tecnologia e à quantificação dos benefícios gerados.

A estratégia competitiva não se apresentou como opção e sim como necessidade muito próxima dos auditores. Logo as dificuldades, quaisquer que sejam, para incorporar a nova concepção, deverão ser discutidas, analisadas e superadas. Trabalhar sob a ótica do cliente parece ser uma dimensão nova para esses profissionais, acostumados a raciocinar como elementos externos ao processo. Aparentemente será preciso esforço maior para entender que, a partir deste momento, passam a integrar o negócio do cliente na consecução dos objetivos mais amplos da empresa.

Dada a impossibilidade de esgotamento do tema, pois muitas outras perguntas e desdobramentos poderiam ser feitos, e dentro das limitações da pesquisa realizada, entende-se que pesquisas futuras possam aprofundar o assunto e, até mesmo, que esta possa ser estendida a outras localidades do país, evitando, assim, generalizações incompatíveis com a postura científica e limitadas à visão regional.

A continuidade deste estudo se justifica, ainda, pela necessidade de avaliar o impacto do pleno cumprimento da IN CVM 308/99, tendo em vista que alguns aspectos, tais como, a proibição da atividade de Auditoria e Consultoria ao mesmo cliente, deixaram de ser aplicados por força de liminares judiciais e outros, como o rodízio obrigatório o qual entrará em vigor apenas em janeiro de 2004. A Sarbanes - Oxley, também, não está consolidada, tendo em vista que foi criada uma comissão

\footnotetext{
${ }^{4}$ De se notar que o assunto "rodízio de auditores" ressurgiu com intensidade no segundo semestre de 2003 a partir de demandas de segmentos do mercado de capitais para que a exigência da CVM fosse extinta. Esses fatos são posteriores à pesquisa que fundamentou o presente artigo e, portanto, não são aqui abordados.
} 
de executivos das principais empresas americanas para propor ao governo medidas adicionais àquelas propostas por referida lei. Por outro lado, esta influirá, também em nível mundial, não só pelo poder econômico dos Estados Unidos, como também pelas regras que incluem empresas estrangeiras, criando, assim, conflitos regulatórios entre países.

Reafirme-se que o referencial que não pode ser perdido é o de que na perspectiva da Auditoria, conforme mencionado anteriormente, a visão de cliente não é excludente. Como clientes se entendem, também, os demais usuários e canais que, na administração de elos da Auditoria, também compartilham valor.

\section{REFERÊNCIAS BIBLIOGRÁFICAS}

CARVALHO, L. Nelson G. O parecer dos auditores independentes sobre demonstrações contábeis no Brasil: estudo das limitações ao seu poder de comunicação. 1989. Dissertação (Mestrado em Controladoria e Contabilidade) - Faculdade de Economia, Administração e Contabilidade, Universidade de São Paulo. São Paulo.

Uma contribuição à auditoria do risco de derivativos. 1996. Tese (Doutorado em Controladoria e Contabilidade) - Faculdade de Economia, Administração e Contabilidade, Universidade de São Paulo. São Paulo.

CONSELHO FEDERAL DE CONTABILIDADE. Normas de auditoria independente. Resolução no. 820 de 17.12.97.

CONSELHO FEDERAL DE CONTABILIDADE. Normas profissionais do auditor independente. Resolução no. 821 de 17.12.97.

GALE, Bradley T. Gerenciando o valor do cliente: criando qualidade e serviços que o cliente pode ver. São Paulo: Pioneira, 1996.

CITADINI, Antonio Roque. Auditoria x consultoria: uma questão ética. Gazeta Mercantil de 18 de outubro de 1999.

FOLHA DE S. PAULO. Firmas de contabilidade criticam limites. São Paulo: 27 de abril de 2000.

GARCIA, Elias. O auditor, a ética profissional e o relacionamento com o mercado. Horizontes da Contabilidade no. 1 volume 1, 2001.

LAKATOS, Eva Maria \& MARCONI, Marina de Andrade. Metodologia do trabalho científico. 4ª . ed., São Paulo: Atlas, 1992.

LEVIN, Jack. Estatística aplicada às ciências humanas. São Paulo: Harbra, 1987.

NOTA:

Endereço dos autores:

L. NELSON CARVALHO

Av. Prof. Luciano Gualberto, 908 - Prédio 3

Cidade Universitária

São Paulo - SP

05508-900

RUTH C. DE S. PINTO

Caixa Postal 6025

Campus do $\mathrm{PICl}$

Fortaleza - CE

$60455-970$

\section{BIBLIOGRAFIA COMPLEMENTAR}

MALHOTRA, Naresk K., Pesquisa de marketing. Porto Alegre: Bookman, 2001.

MONTGOMERY, Cynthia A. \& PORTER, Michael E. Estratégia. Rio de Janeiro: Campus, 1998.

PINHO, Ruth Santana. A Manutenção da Independência em Face das Estratégias Mercadológicas de Satisfação do Cliente - Um Estudo Exploratório da Região Nordeste. 2001. Dissertação (Mestrado em Controladoria e Contabilidade) - Faculdade de Economia, Administração e Contabilidade, Universidade de São Paulo. São Paulo.

PORTER, Michael E. Estratégia: em busca da vantagem competitiva. Rio de Janeiro: Campos, 1998.

TÉBOUL, JAMES. A era dos serviços. Rio de Janeiro: Qualitymark, 1999.

RICHARDSON, Roberto Jarry. Pesquisa social: métodos e técnicas. São Paulo: Atlas, 1999.

SENGER, Clemildo Aparecido. A necessidade de mudar o enfoque da auditoria: um estudo sobre as "Big Six". São Paulo:1998. Dissertação de Mestrado FEA /USP.

SLYWOTZKY, Adrian J. \& MORRISON David J. A estratégia focada no lucro. Rio de Janeiro: Campus, 1998.

VANASCO, Rocco R. Auditor independence: an international perspective. Managerial Auditing Journal, volume 11. issue 9, 1996.

WHITLEY, Richard \& HESSAN, Diane. Customer centered growth. Massachusetts: Adddison Wesley, 1996. 